\title{
Usability Study of Enhanced Salat Learning Approach using Motion Recognition System
}

\author{
Nor Azrini Jaafar, Nor Azman Ismail, and Yusman Azimi Yusoff \\ Faculty of Engineering, Universiti Teknologi Malaysia, Malaysia
}

\begin{abstract}
Salat learning is one of the most important processes for every Muslim. The current learning approach requires the teacher or expert to be present in the learning session, which is time and resource-consuming. Previous researchers use both wearable and non-wearable sensors to recognize salat movement. They focus on specific salat movement rather than complete salat movement cycle. This paper present a motion recognition system to enhance salat learning experience. The system helps users recognize the complete salat movements cycle based on salat law by using a multisensor setup for better tracking capability. Three evaluations are conducted to validate the system's performance and its contribution. The first evaluation is to measure success score in recognition accuracy and identify user error. The second evaluation is conducted to compare the proposed system with the traditional-based methodology, and the last evaluation focuses on the user experience and acceptance of the proposed system. The result from performance evaluation shows the system has high accuracy in recognizing salat movement. There is a significant difference in the error rate and success score when comparing the learning methodology. However, users provide positive feedback based on the survey conducted after using the proposed system.
\end{abstract}

Keywords: Salat Learning, motion recognition, salat law, learning methodology.

Received February 20, 2021; accepted March 7, 2021

https://doi.org/10.34028/iajit/18/3A/4

\section{Introduction}

Research on human movement recognition began decades ago [17]. It starts by using wearable sensors [7] that allow the recognition is done accurately. However, wearable sensors are not as desirable because of expensive, complicated, and hard to maintain [21]. For the past years, researchers worldwide have done much research regarding human motion $[8,24,25,31]$ as this topic can be explored extensively, and a variety of applications can be produced from it. Many approaches have been proposed from the simple setup procedures toward stable, accurate, and real-time motion capturing and recognition [29].

Salat is one obligation required for Muslims to do in their daily life. Every day, Muslims perform salat five times in a day. Salat is not only about the spiritual act but involves physical movement that should be followed mannerly. Salat movement is an unexplored area in motion recognition as there is no existing database regarding salat motion. Existing databases on motion recognitions are limited [11], limiting the research in this spiritual activity area. There is nine sequence movement in salat activity, a complete cycle known as raka'ah as shown in Figure 1.

This paper presents a usability study on a motion recognition system named SalatLab using a cooperative multisensor approach. In this paper, the user's error rate and success score on motion recognition were evaluated by the SalatLab prototype. The result will then be compared with the tutor-based method to test if the proposed system can bridge the gap in assessing user error. The experiment was also conducted to evaluate user experience and acceptance toward the proposed prototype.

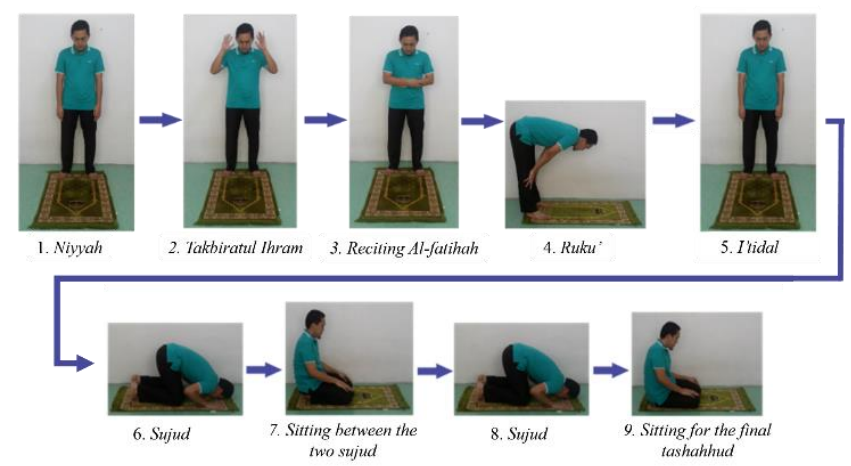

Figure 1. The sequence of complete raka'ah in salat.

\section{Literature Review}

In earlier years, a real-time motion recognition system required the user to wear unique clothes or costumes as markers [6]. However, these marker-based applications are high maintenance and not desirable by the user. Thus, it makes marker-less motion recognition applications are in high demand. The marker-less motion recognition system [18] has progressed rapidly in these recent years as technology advances rapidly. Occlusion and ambiguity in single-camera motion tracking can be resolve by using multiple cameras. 
With multiple cameras, ambiguity and occlusion can be resolved as the system gets multiple human body perspectives.

For many years, the salat learning method used textbook as their primary references. These learning approaches are less effective in attracting students' concentration and not motivating the students' interest. When the students do not understand the teacher's lecture, some tend to stay quiet and not ask questions. Some schools require students to do it in the congregation to encourage the students to perform salat. However, some students refuse and avoid praying. The school has done various measures and methods to address this problem, such as taking students' attendance to prayer room; teachers observe students practice and reduce scoring penalties. The various parties should give salat practices among students serious attention. This is because salat duty is a fundamental responsibility of Muslim before other obligations in the pillars of Islam [30].

In Malaysia, Salat Smart Camp, known as Kem Bestari Solat (KBS), is a program of modules introduced in the co-curricular jawi, Quran, Arabic and Fardhu ain (j-QAF) program, to enhance students' salat. This program is part of the Islamic and Moral Education Department curriculum under the Ministry of Education (MOE). It has undertaken several measures to ensure that all students can perform salat properly, particularly by them in year 6 . This approach seeks to intensify the implementation of the latest methods of teaching Islamic education in line with current developments [2].

Through the j-QAF program, the KBS is an academic curricular activity that includes all Muslim students in primary school to ensure that they can perform the obligation of daily prayers correctly in terms of readings, acts and practices. The school administrators and teachers have been responsible for ensuring the program is implemented as specified. Recent back-through in technology have made some researchers and creative content companies collaborate with educators and come out with new ways of learning approaches such as interactive e-books that offer more interactive. Although this method was able to attract students to learn by themselves, technically, this way cannot guarantee the correctness in salat movement. This is because there is no observer, such as the teacher, to observe and advise if they perform the salat wrongly.

With the advent of converged mobile technologies, there are lots of applications that support mobile learning. Google Play provides many free applications to help Muslims learn basic knowledge of salat and how to perform it. However, the application is limited because it just illustrates the step-by-step method and posture to perform salat. Recently, many research was conducted about salat. There is no research on salat movement based on human motion tracking and analysis for assisting salat learning. Table 1 summarize existing salat learning research.
Table 1. Summary of existing salat learning.

\begin{tabular}{|c|c|c|}
\hline Method & Author & Finding \\
\hline \multirow[t]{3}{*}{$\begin{array}{c}\text { Application } \\
\text { Development }\end{array}$} & Rosmani et al. [27] & $\begin{array}{l}\text { Developed 3D application with } \\
\text { guideline and therapeutic means } \\
\text { on salat movement }\end{array}$ \\
\hline & Lee and Mase [22] & $\begin{array}{l}\text { Develop a mobile application as } \\
\text { a guide to the Muslim of all ages } \\
\text { to perform prayers }\end{array}$ \\
\hline & Khalid et al. [19] & $\begin{array}{l}\text { Propose a mobile learning } \\
\text { framework to learn salat }\end{array}$ \\
\hline Multimedia & Alias and Aziz [4] & \begin{tabular}{|c|} 
Applied multimedia and \\
simulation concept to develop \\
interactive computerized \\
simulation software to illustrate \\
body movement and blood \\
circulation during salat. \\
\end{tabular} \\
\hline \multirow[t]{2}{*}{ Sensor-based } & Ismail et al. [13] & $\begin{array}{l}\text { Present the description and } \\
\text { design of Smart Prayer Mat to } \\
\text { help elderly Muslim with } \\
\text { cognitive impairment. Sending } \\
\text { signal when they complete the } \\
\text { salat cycle }\end{array}$ \\
\hline & Ahmad et al. [1] & $\begin{array}{l}\text { Proposed salat activities } \\
\text { recognition model using a } \\
\text { mobile sensor to help people } \\
\text { suffering from Alzheimer. }\end{array}$ \\
\hline Board Game & Manaf et al. [23] & $\begin{array}{c}\text { Create a board game name } \\
\text { Monopoli Solat as a tool to help } \\
\text { student memorize salat } \\
\text { recitations. }\end{array}$ \\
\hline
\end{tabular}

Many previous research has done motion recognition into daily activities such as surveillance [20], rehabilitation [5], and sports training [10]. Inspired by previous research, this paper presented a proposed prototype using motion recognition for the Muslim salat movement. A few researchers have done existing research on the salat movement. El-Hoseiny and Shaban [9] have done the Muslim Prayer Action Recognition system capable of recognizing major postures and actions performed during salat. The system was tested against a custom data set accuracy of 93.5\% was recorded. In this Muslim prayer action recognition research, the system using a single camera that classifies some posture such as ruku', sujud, and standing only. More salat movement can be classified using multiple cameras such as Takbiratul Ihram.

By using multiple cameras, the detection and validation of front, side, or back postures can be done to check correct movement in salat activities. Ismail et al. [13] presented their work in intersections of technological development and spiritual practice by introducing the smart prayer mat. They present the description and design a smart prayer mat that is embedded with a textile-based sensor that prompts audible cues to alert elderly Muslims with cognitive impairment. The mat will prompt audible signals when the salat cycle or raka'ah has been completed. This will alert the elderly as they completed the salat.

With the increase of mobile smartphone sensors, AlGhannam and Al-Dossari [3] had the idea to detect users' actions from a series of observations regarding users' body movements. They introduced a mobilebased application to monitor and recognize prayer activities using the mobile phone acceleration features. 
However, this research can only determine the correctness of four main prayer tasks as standing bowing, prostration, and sitting. It determines the correctness of the prayer by checking the completeness and order of tasks. Hamzah et al. [12] proposed developing and incorporating a prayer-learning application with multimedia elements to attract children. The existing research on salat movement can be summarized in Table 2 below.

Table 2. Summary of existing salat research.

\begin{tabular}{|c|c|c|c|}
\hline Author & Title & $\begin{array}{c}\text { Motion } \\
\text { Recognition }\end{array}$ & $\begin{array}{c}\text { Assisted } \\
\text { Salat @ } \\
\text { Learning }\end{array}$ \\
\hline $\begin{array}{c}\text { El-Hoseiny and } \\
\text { Shaban [9] }\end{array}$ & $\begin{array}{c}\text { Muslim Prayer Actions } \\
\text { Recognition }\end{array}$ & $/$ & \\
\hline Ismail et al. [13] & $\begin{array}{c}\text { Smart Prayer Mat: A Textile- } \\
\text { Based Pressure Sensor to Assist } \\
\text { Elderly with Cognitive } \\
\text { Impairment in Praying Activity }\end{array}$ & $/$ \\
\hline $\begin{array}{c}\text { Al-Ghannam and } \\
\text { Al-Dossari [3] }\end{array}$ & $\begin{array}{c}\text { Prayer Activity Monitoring and } \\
\text { Recognition Using } \\
\text { Acceleration Features with } \\
\text { Mobile Phone }\end{array}$ & $/$ & \\
\hline Hamzah et al. [12] & $\begin{array}{c}\text { Android Application for } \\
\text { Children to Learn Basic Solat }\end{array}$ & & / \\
\hline
\end{tabular}

None of the research combine motion recognition to assist or improve salat learning, and research that focuses on facilitating salat learning used another option instead of salat motion recognition. Recent advances in technology have made data collection tasks easier, thus motivating us to work on this research. The focus of the study are:

- To develop a motion recognition system for salat movement that able to recognize salat movement and evaluate user error rate.

- To be compared with the traditional tutor-based methodology.

- To evaluate user experience and satisfaction toward motion recognition system approach.

\section{System Overview}

To track and recognize salat movement, a dual Kinect had been used as the primary sensor. In salat movement, there are 13 main movements or tasks required to complete two cycles of raka'ah. According to the salat law, seven body parts must touch the ground or prayer mat for sujud movement: forehead, two palms, two knees, and two feet. For this movement, seven sensors are located on the prayer mat to detect seven body parts complement the Kinect sensor. Figure 2 below showed a combination of a dual Kinect sensor and multi-switch sensor at the prayer mat known as a cooperative multisensor setup. To determine the best location of dual Kinect sensors, an initial set of experiments was conducted in the optimal place. Data were collected from four different dual Kinect sensors setup as illustrated in Figure 3 below.

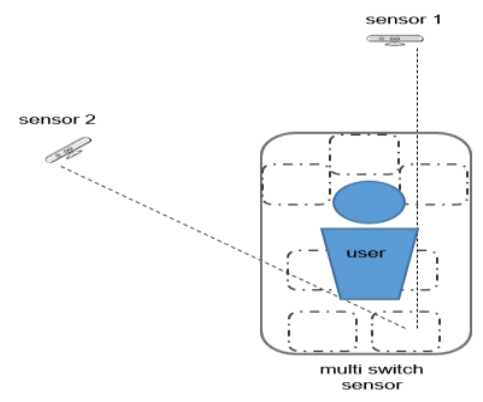

Figure 2. Cooperative multisensor setup.
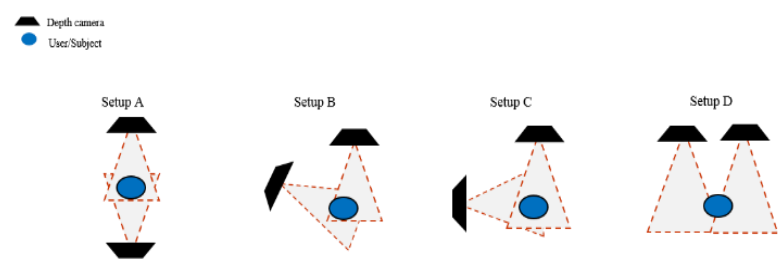

Figure 3. Multiple kinect setups.

The optimal place is important for better recognition and analytic results for salat movement activities. The experiment results concluded that setup B was the optimal sensor setup to recognize motion in salat activity as it was the highest accuracy in recognizing salat movement. The result and discussion have been presented and discussed in [14]. Besides, the experiment proved that not all sensor setups are suitable for motion recognition in salat activity.

We used joint information provided by Kinect Software Development Kit (SDK) to determine the joint position for tracking purposes. From this information, the important joints that significant movement during salat movement was selected as features for Hidden Markov Model (HMM) to classify into 13 main movements. These features will be used for the training and testing process.

The important joins were selected from the joint information were the right and left wrist, head, middle spine, and bottom spine. Instead of others, these joints were chosen because they have a significant movement during salat activity [16]. Since existing databases are limited and there was no salat movement data, we manually collected the data for all salat activity movements.

HMM is widely known in pattern recognition and used in speech recognition in early research [26]. HMM is a sequence where the sequence of state is hidden. The parameter can represent it $\lambda=(\mathrm{n}, \mathrm{A}, \mathrm{B}, \pi)$. In motion recognition with depth sensor and HMM, a set of motion recognition in salat activity was modeled to be trained in $\mathrm{N}$ states. Figure 4 below shows where the number of state $\mathrm{N}$ can be decided according to movement context. In this case, there are seven states of HMM model in the salat movement. Each circle represents a state, representing the probability density function of transition from state one state to another state. 


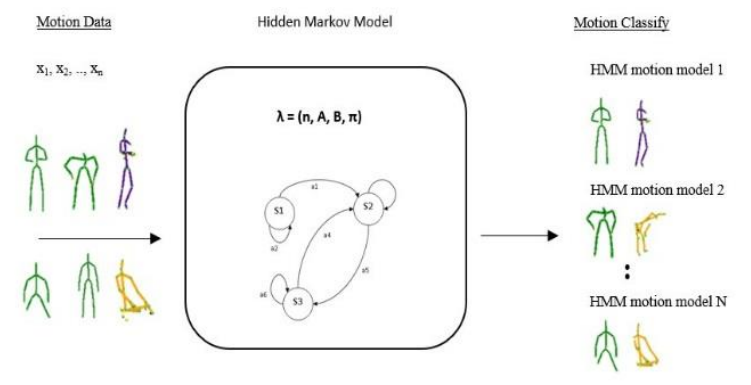

Figure 4. HMM function in motion classification.

When performing gesture recognition, the trained HMM motion model established from the training phase is used to classify motion categories and estimate the class for test motion data. Unlike automated speech recognition, motion recognition with HMM needs to define the motion model's state sequences in an active scene frame. As mentioned before, each HMM state sequence in the motion model needs to be defined so that the motion can be recognized as HMM motion model. We used voice activation to get start-frame from continuous-time motion data from an active user to deploy the method such as in automated speech recognition. Figure 5 below shows the recognition scheme employed in this HMM motion recognition. When the user makes an indicated class of motion, only motions in the motion recognition frame will be used to perform the recognition process. The end-frame from this active motion data will be captured after 3 seconds from the start frame to fulfill the requirement's salat laws. The other motion frame not contained in the margin of motion recognition frame should be neglected.

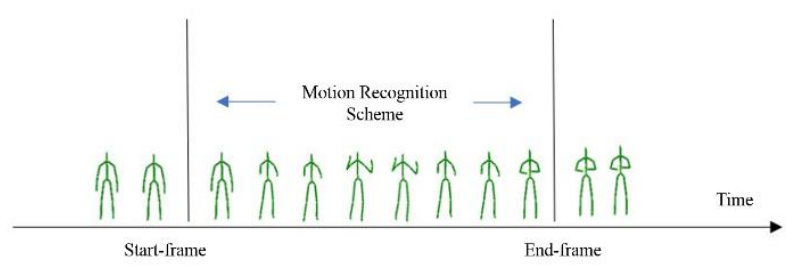

Figure 5. Recognition scheme with HMM.

The integration of cooperative multisensor and HMM lead to the development of an algorithm for salat movement recognition. This algorithm is used to classify 13 main tasks in salat activity accurately. First, the data set is recorded using the designed setup. Fifteen motion data is recorded for each of the salat activities. Data set are stored in the motion database.

Ten random motion data set per salat activity are pulled from the database to train the model. Once the training process is finished, the remaining five motion data set are extracted to be used in the model validation process.

\section{Experimental Design}

The user's error rate in salat activity is the main indicator in the experimental evaluation. This indicator is measured using the conventional tutor-based and developed prototype method. 25 Muslim students with knowledge of performing salat are selected as the participants for the experiment. All participants are verified that they do not have experience in any related experiment previously.

The experiment was set up and conducted in a specialized experiment room to prevent any unforeseen disruption. The layout of the setup is illustrated in Figure 6. Do note that only one participant is permitted for each of the experiment sessions. During the experiment, the video stream from the sensor is saved and later used by the tutor to check and evaluate participants' salat activity.

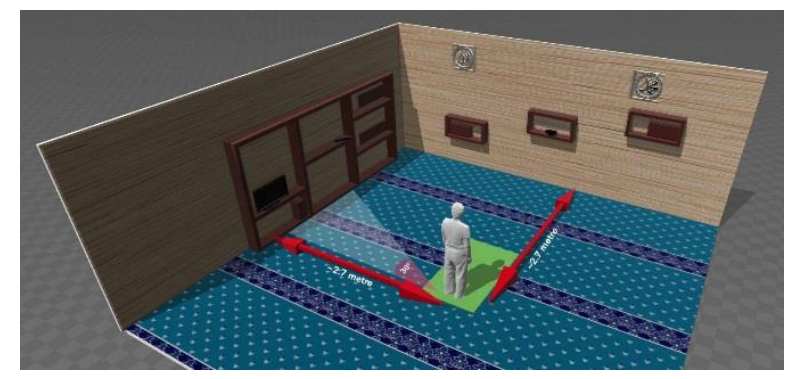

Figure 6. Prototype setting.

Each participant was given a short briefing about the experiment procedures and how to interact with the prototype. The participant is encouraged to perform salat naturally without worrying about the prototype during the experiment. A factorial design is applied within the group where every participant has given two condition independent variables. The first condition is related to the interaction between participant and prototype, while the second condition is solely related to the tutor's evaluation. Natural salat activity is emphasized to the participant to ensure that the experimental setup does not affect their salat activity quality. The steps taken to conduct the experiment are as follow:

1. The researcher gives a short explanation about the experiment and asks participants to fill in a questionnaire.

2. Information about prototype functionality is explained, and participants are advised to perform salat as natural as possible.

3. Participants require to perform two raka'ah cycles. The movement result analyzed by the prototype is presented to the participant once they finished the process.

4. The participant is required to rate the prototype after viewing the movement result for subjective satisfaction feedback. 


\section{Data Analysis}

Twenty-five participants took part in the evaluation. Each of the participants was given a set of questionnaires that assessed their background in salat. The information included age, educational background, and their daily salat activity. The majority of the participants were undergraduate students (20 participants), with only four postgraduate students and one research assistant. They are comprised of 21 to 28 years old. All of them reported to have done prayer daily and have knowledge in the computer system.

This experiment aims to identify the relationship between traditional tutor-based evaluation and proposed prototyping to detect and evaluate user error rates and success scores in recognizing salat movements. Thus, the null hypotheses are concluded as follow:

a. Error Rate H1: There is no difference in error rate between proposed prototype salat monitoring and tutor-based monitoring.

b. Success Score H2: There is no difference in success score between proposed prototype salat monitoring and tutor-based monitoring.

The number of errors made by the users was counted and detected separately. The error here refers to user error, as doing extra movement and a short time in transition between two movements counted as toma'ninah as in the salat rule. Figure 7 below show error made by the user evaluated by SalatLab and tutor.

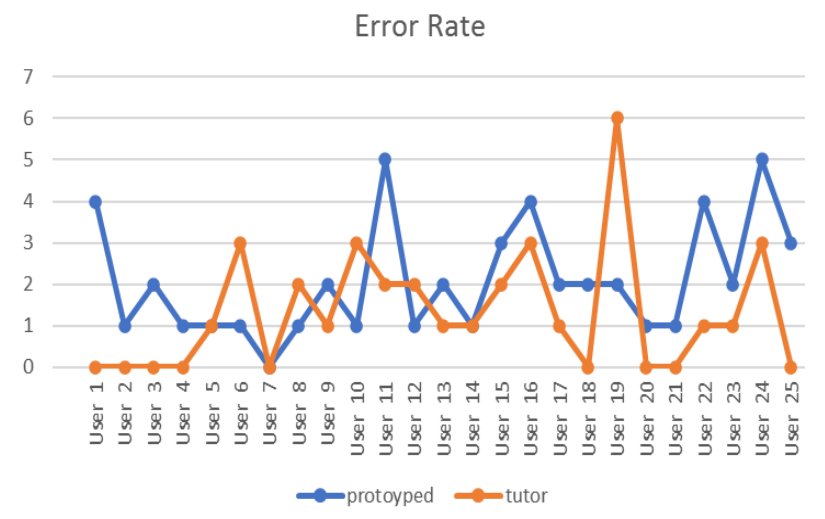

Figure 7. User error rate.

A paired t-test was conducted to compare the error rate and success score detected by the proposed prototype and traditional tutor-based. The t-value was calculated using the Equation:

1. Standard Deviation of Sample Differences.

2. Standard Error of Sample Differences.

3. T Statistic for Paired-Sample t-test.

$$
\begin{gathered}
S D_{D}=\sqrt{\frac{\sum\left(D-M_{D}\right)^{2}}{N-1}}=\sqrt{\frac{S S_{D}}{N-1}} \\
S E_{D}=\frac{S D_{D}}{\sqrt{N}}
\end{gathered}
$$

$$
t=\frac{\left(M_{D}-\mu_{D}\right)}{S E_{D}}
$$

Table 3 shows the summary of results compared to the developed prototype and tutor in terms of user error rate. From the table, it can be conclude that there is significant different between proposed prototype

$(\mathrm{M}=2.08, \quad \mathrm{SD}=1.382)$ and traditional tutor-based $(\mathrm{M}=1.36, \mathrm{SD}=1.464 ; \mathrm{t}(24)=2.127, \mathrm{p}=0.044)$. Since $\mathrm{p}<$ 0.05 , the null hypothesis $(\mathrm{H} 1)$ is rejected.

Table 4 shows the summary of results compared to the developed prototype and tutor in terms of success score in recognizing salat movements. From the table, that can be conclude that there is significant different between proposed prototype $(\mathrm{M}=10.92, \mathrm{SD}=2.216)$ and traditional tutor-based $(\mathrm{M}=12.88, \mathrm{SD}=0.6 ; \mathrm{t}(24)=-4.16$, $\mathrm{p}=0.0003)$. Since $\mathrm{p}<0.05$, thus the null hypothesis $(\mathrm{H} 2)$ is rejected

Table 3. User error rates.

\begin{tabular}{|c|c|c|c|c|c|}
\hline & $\begin{array}{c}\text { Prototyped } \\
\text { Mean } \\
\text { (SD) }\end{array}$ & $\begin{array}{c}\text { Tutor Mean } \\
\text { (SD) }\end{array}$ & t-value & Df & $\begin{array}{c}\text { 2-tailed } \\
\text { sig. }\end{array}$ \\
\hline Error Rate & $\begin{array}{c}2.08 \\
(1.382)\end{array}$ & $\begin{array}{c}1.36 \\
(1.464)\end{array}$ & 2.127 & 24 & 0.044 \\
\hline
\end{tabular}

Table 4. success score.

\begin{tabular}{|c|c|c|c|c|c|}
\hline & $\begin{array}{c}\text { Prototyped } \\
\text { Mean } \\
\text { (SD) }\end{array}$ & $\begin{array}{c}\text { Tutor } \\
\text { Mean } \\
\text { (SD) }\end{array}$ & t-value & Df & $\begin{array}{c}\text { 2-tailed } \\
\text { sig. }\end{array}$ \\
\hline $\begin{array}{c}\text { Success } \\
\text { Score }\end{array}$ & $\begin{array}{c}10.92 \\
(2.216)\end{array}$ & $\begin{array}{c}12.88 \\
(0.6)\end{array}$ & -4.16 & 24 & 0.0003 \\
\hline
\end{tabular}

A User Experience Questionnaire (UEQ) is used as part of the classical usability test to collect some quantitative data about the participants' impression concerning user experience. The original German version of the UEQ was created back then in 2005 [28]. The data analytical approach was used to ensure the constructed scales' practical relevance. Each scale describes a distinct quality aspect of the interactive product. The best time to handle the questionnaire to participants is directly after they finished working on the test task. The UEQ was given to all 25 participants after they tried and used the proposed prototype

The result from the UEQ shown the proposed prototype has fulfilled the general expectations concerning user experience, as all scales show a positive evaluation, as shown in Figure 8. Meanwhile, Figure 9 shown the benchmark graph for the proposed prototype. The proposed prototype was rated above average, which is Good and Excellent. 


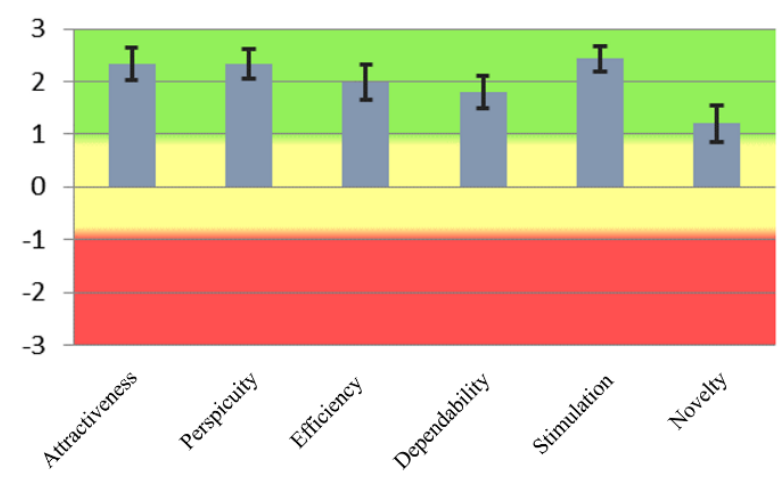

Figure 8. Result from the UEQ.

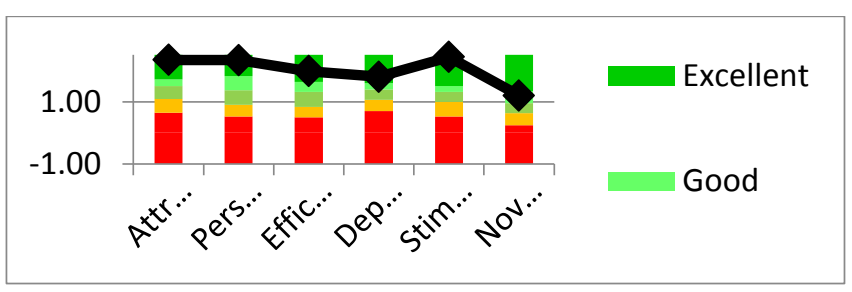

Figure 9. Benchmark graph for the proposed prototype.

A set of System Usability Scale (SUS) questions were given for the experiment's proposed prototype. The questions were given only to the proposed prototype because the participant did not have direct experiences with the tutor-based. The individual score for the tested prototype is also plotted in Figure 10 below. The lowest score was rated by one user among 25 people, which is 45. The average SUS score for this prototype is 70.5 , which is higher than the average score of acceptable SUS. The result shows that the developed prototype was accepted positively by the user. Besides, there were several positive feedback and suggestion from the user, as stated in Table 5. All of the work had been discussed and presented in [15].

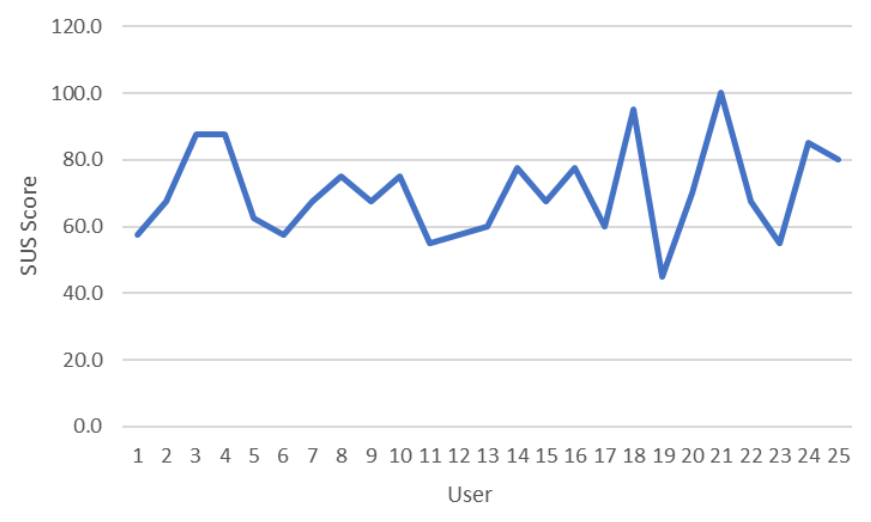

Figure 10. SUS score by user.
Table 5. User feedback and suggestion.

\begin{tabular}{|c|l|}
\hline User & Feedback and Suggestion \\
\hline User 8 & "It is so easy to learn to use this application." \\
\hline User 9 & $\begin{array}{l}\text { "It would be good if this application to have a } \\
\text { mobile application to send the result of prayer } \\
\text { to the user." }\end{array}$ \\
\hline User 10 & $\begin{array}{l}\text { "It would be nice if this application detects the } \\
\text { motion automatically using movement rather } \\
\text { than voice." }\end{array}$ \\
\hline User 11 & $\begin{array}{l}\text { "I like this invention because it can correct my } \\
\text { mistake when performing salat. " }\end{array}$ \\
\hline User 21 & $\begin{array}{l}\text { "I hope this application can be detected better } \\
\text { on ruku' or sujud movement. " }\end{array}$ \\
\hline User 23 & $\begin{array}{l}\text { "This is a good application. I hope it can benefit } \\
\text { the ummah." }\end{array}$ \\
\hline User 24 & $\begin{array}{l}\text { "This is a good incentive to improve the way of } \\
\text { salat." }\end{array}$ \\
\hline
\end{tabular}

\section{Conclusions}

In this paper, the data from the evaluation of the prototype and comparison with teacher-based was presented. The prototype data by 25 participants was compared with teacher-based consisting success score and user's error rate. Then, the prototype was evaluated by 25 participants consisting of user's experience and subjective satisfaction toward the prototype. The data was gathered after the prototype evaluation session using UEQ and SUS. Statistical analysis was employed to compare the data gathered by prototype with the traditional method of teacher-based evaluation. This study also examined the first-time usage of motion recognition on salat movement analysis. Based on user experience question and SUS, this proposed prototype was been accepted to be used in salat learning. These results are valuable since it can improves the existing proposed prototype and reduce the gap with the traditional teacher-based method by design better algorithm. Table 6 shows the list of the null hypotheses accepted or rejected.

Table 6. List of null hypotheses explored.

\begin{tabular}{|c|c|c|c|}
\hline N1 & $\begin{array}{c}\text { Null Hypotheses (H) explored } \\
\text { prope is significant difference between } \\
\text { proposed prototype and teacher based } \\
\text { evaluation on recognizing salat } \\
\text { movement. }\end{array}$ & 0.0003 & R/A \\
\hline H2 & $\begin{array}{c}\text { There is significant difference between } \\
\text { proposed prototype and teacher based } \\
\text { evaluation on detecting user error. }\end{array}$ & 0.0438 & $\mathrm{R}$ \\
\hline Sig. & & \\
\hline
\end{tabular}

$$
\mathrm{R} / \mathrm{A}=\mathrm{R} \text { (Rejected) or A (Accepted) }
$$

\section{References}

[1] Ahmad N., Han L., Iqbal K., Ahmad R., Abid, M., and Iqbal N., "SARM: Salah Activities Recognition Model Based on Smartphone," Electronics, vol. 8, no. 8, pp. 1-24, 2019.

[2] Ahmad F. and Tamuri H., "Persepsi Guru Terhadap Penggunaan Bahan Bantu Mengajar Berasaskan Teknologi Multimedia Dalam Pengajaran J-QAF," Journal of Islamic and Arabic Education, vol. 2, no. 2, pp. 53-64, 2010. 
[3] Al-Ghannam R. and Al-Dossari H., "Prayer Activity Monitoring and Recognition Using Acceleration Features with Mobile Phone," Arabian Journal for Science and Engineering, vol. 41, no. 12, pp. 4967-4979, 2016.

[4] Alias A. and Aziz N., "Implementing Multimedia and Simulation in Developing Computerized Blood Circulation and Bodily Movement During Obligatory Prayers," in Proceedings of $2^{\text {nd }}$ International Conference on Computer Technology and Development, Cairo, pp. 735-738, 2010.

[5] Bo A., Hayashibe M., and Poignet P., "Joint Angle Estimation in Rehabilitation with Inertial Sensors and Its Integration with Kinect," in Proceedings of The Annual International Conference of the IEEE Engineering in Medicine and Biology Society, Boston, pp. 3479-3483, 2011.

[6] Calvert T., Chapman J., and Patla A., "Aspects of The Kinematic Simulation of Human Movement," IEEE Annals of the History of Computing, vol. 2, no. 09, pp. 41-50, 1982.

[7] Cutting J. and Kozlowski L., "Recognizing Friends by Their Walk: Gait Perception without Familiarity Cues," Bulletin of the psychonomic Society, vol. 9, no. 5, pp. 353-356, 1977.

[8] Dockstader S. and Tekalp A., "Multiple Camera Tracking of Interacting and Occluded Human Motion," in Proceedings of the IEEE, vol. 89, no. 10, pp. 1441-1455, 2001.

[9] El-Hoseiny M. and Shaban E., "Muslim Prayer Actions Recognition," in Proceedings of The Second International Conference on Computer and Electrical Engineering, Dubai, pp. 460-465, 2009.

[10] Fung S., Sundaraj K., Ahamed N., Kiang L., Nadarajah S., Sahayadhas A., Ali A., Islam A., and Palaniappan R., "Hybrid Markerless Tracking of Complex Articulated Motion in Golf Swings," Journal of Bodywork And Movement Therapies, vol. 18, no. 2, pp. 220-227, 2014.

[11] Guerra-Filho G. and Biswas A., "The Human Motion Database: A Cognitive and Parametric Sampling of Human Motion," Image and Vision Computing, vol. 30, no. 3, pp. 251-261, 2012.

[12] Hamzah N., Halim N., Hassan M., and Ariffin A., "Android Application for Children to Learn Basic Solat," International Journal of Interactive Mobile Technologies, vol. 13, no. 7, pp. 69-79, 2019.

[13] Ismail J., Noor L., and Rahim A., Isa M., "Smart Prayer Mat: A Textile-Based Pressure Sensor to Assist Elderly with Cognitive Impairment in Praying Activity," in Proceedings of $5^{\text {th }}$ International Conference on Computing and Informatics, Istanbul, pp. 241-246, 2015.

[14] Jaafar A., Ismail N., Jasmi K., and Yusoff Y., "Optimal Dual Cameras Setup for Motion Recognition in Salat Activity," The International
Arab Journal of Information Technology, vol. 16, no. 6, pp. 1082-1089, 2019.

[15] Jaafar N., Ismail N., and Yusoff Y., "A New Approach in Islamic Learning: Performance Evaluation of Motion Recognition System for Salat Movement," in Proceedings of $21^{\text {st }}$ International Arab Conference on Information Technology, $6^{\text {th }}$ of October city, pp. 1-6, 2020.

[16] Jaafar N., Ismail N., and Yusoff Y., "An Investigation Of Motion Tracking For Solat Movement With Dual Sensor Approach," ARPN Journal of Engineering and Applied Sciences, vol. 10, no. 23, pp. 17981-17986, 2015.

[17] Johansson G., "Visual Perception of Biological Motion and A Model for Its Analysis," Perception and Psychophysics, vol. 14, no. 2, pp. 201-211, 1973.

[18] Kehl R. and Van Gool L., "Markerless Tracking of Complex Human Motions from Multiple Views," Computer Vision and Image Understanding, vol. 104, no. 2-3, pp. 190-209, 2006.

[19] Khalid N., Jaafar H., and Kasbun R., "Developing A Mobile Learning Application Framework of 'Jamak Qasar Apps, Using ADDIE Approach," Australian Journal of Basic and Applied Sciences, vol. 9, no. 19, pp. 40-44, 2015.

[20] Lam K. and Chiu C., "The Design of A Wireless Real-Time Visual Surveillance System," Multimedia Tools and Applications, vol. 33, no. 2, pp. 175-199, 2007.

[21] Lam K. and Chiu C., "The Design of A Wireless Real-Time Visual Surveillance System," Multimedia Tools and Applications, vol. 33, no. 2, pp. 175-199, 2007.

[22] Lee S. and Mase K., "Activity and Location Recognition Using Wearable Sensors," IEEE Pervasive Computing, vol. 1, no. 3, pp. 24-32, 2002.

[23] Manaf S., Zaid A., Din R., Hamdan A., Salleh N., Kamsin I., Karim A., and Lubis M., "Aplikasi Mudah Alih Panduan Solat dan Penggunaannya," Ulum Islam Journal, vol. 16, pp. 43-61, 2015.

[24] Moore D., "A Real-World System for Human Motion Detection and Tracking," California Institute of Technology, pp. 3-36, 2003.

[25] Okada S. and Hasegawa O., "Motion Recognition Based on Dynamic-Time Warping Method with Self-Organizing Incremental Neural Network," in Proceedings of The $19^{\text {th }}$ International Conference on Pattern Recognition, Tampa, pp. 1-4, 2008.

[26] Picone J., "Continuous Speech Recognition Using Hidden Markov Models," IEEE Assp Magazine, vol. 7, no. 3, pp. 26-41, 1990.

[27] Rosmani A., Zainuddin N., Ahmad S., and Ramli S., "Bio Terapi Solat: 3d Integration in Solat Technique for Therapeutic Means," in Proceedings of The Advanced Computer and 
Communication Engineering Technology, Cham, pp. 1001-1011, 2015.

[28] Schrepp M., Hinderks A., and Thomaschewski J., "Applying The User Experience Questionnaire (UEQ) In Different Evaluation Scenarios," in Proceedings of The International Conference of Design, User Experience, and Usability, Cham, pp. 383-392, 2014.

[29] Shao L., Ji L., Liu Y., and Zhang J., "Human Action Segmentation and Recognition Via Motion and Shape Analysis" Pattern Recognition Letters, vol. 33, no. 4, pp. 438-445, 2012.

[30] Suhid A. and Mutalib L., "Tinjauan Terhadap Pelaksanaan Kem Bestari Solat" Journal of Islamic and Arabic Education, vol. 1, no. 1, pp. 15-28, 2009.

[31] Yamato J., Ohya J., and Ishii K., "Recognizing Human Action in Time-Sequential Images Using Hidden Markov Model," in CVPR, vol. 92, pp. 379-385. 1992.

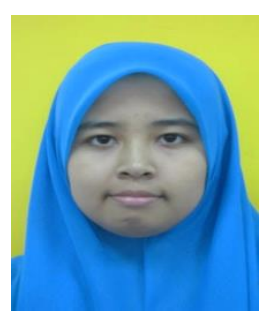

Nor Azrini Jaafar received her bachelor's degree in computer science from Universiti Teknologi Malaysia (UTM) in 2012. Currently, she is doing a Ph.D. in Human-Computer Interaction (HCI). Her research interests include Human-Computer Interaction, motion recognition, and machine learning.

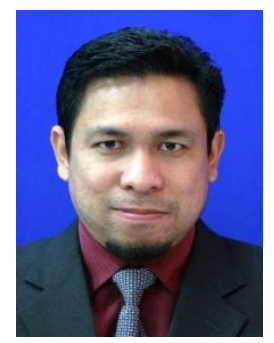

Nor Azman Ismail received his BSc from Universiti Teknologi Malaysia (UTM), Master of Information Technology from Universiti Kebangsaan Malaysia (UKM), and Ph.D. in the field of HumanComputer Interaction (HCI) from Loughborough University. $\mathrm{He}$ has been a lecturer at the Faculty of Computing, Universiti Teknologi Malaysia for more than twenty years. He has made various contributions to the field of HumanComputer Interaction including research, practice, and education.

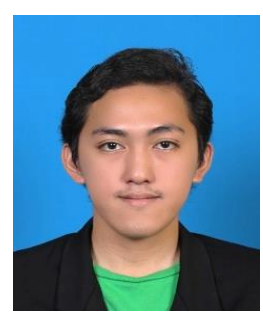

Yusman Azimi Yusoff received his bachelor's degree in computer science in 2013 and Ph.D. in scientific visualization in 2020 from Universiti Teknologi Malaysia. His research interests include machine learning, data visualization, and Internet-ofThings. He has been a Data Scientist at PPG Coating (M) Sdn Bhd since 2019. 